Mycologia, 107(5), 2015, pp. 903-914. DOI: 10.3852/15-062

(C) 2015 by The Mycological Society of America, Lawrence, KS 66044-8897

\title{
First comprehensive phylogenetic analysis of the genus Erysiphe (Erysiphales, Erysiphaceae) II: the Uncinula lineage
}

\author{
Susumu Takamatsu ${ }^{1}$ \\ Hanako Ito (Arakawa) \\ Yoshiaki Shiroya \\ Department of Bioresources, Graduate School, Mie \\ University, 1577 Kurima-Machiya, Tsu 514-8507, \\ Japan \\ Levente Kiss \\ Plant Protection Institute, Centre for Agricultural \\ Research, Hungarian Academy of Sciences (MTA), \\ 1525 Budapest, P.O. Box 102, Hungary \\ Vasyl Heluta \\ M.G. Kholodny Institute of Botany of the National \\ Academy of Sciences of Ukraine, 2 Tereshchenkivska \\ Street, Kiev, 01601, Ukraine
}

\begin{abstract}
Phylogenetic relationships of the Uncinula lineage, which is the basal group in the genus Erysiphe, were investigated with 167 sequences of nuc ITS1-5. 8S-ITS2 and the 28S rDNA regions. Backbone tree analyses with six datasets and two tree-constructing methods revealed that the Uncinula lineage is divided into seven distinct clades. Clades $1-5$ each contained a representative powdery mildew species, namely E. australiana in Clade 1, E. liquidambaris in Clade 2, E. adunca in Clade 3, E. fraxinicola in Clade 4 and E. actinidiae in Clade 5. Clade 6 comprises 71 sequences including the Microsphaera lineage and 17 species of the Uncinula lineage, such as E. carpinicola, E. carpinilaxiflorae, E. miyabei, E. glycines and E. necator. Topology tests supported the Microsphaera lineage forming a monophyletic clade in Clade 6, suggesting that Microsphaera-type appendages appeared only once in this clade to diverge into the Microsphaera lineage. Clade 7 consists of 72 sequences containing 30 species, including species of sects. Californiomyces and Typhulochaeta, four species from Nothofagus, species of sect. Erysiphe parasitising herbaceous plants belonging to the Asteraceae, Rosaceae and Saxifragaceae. Molecular clock analysis suggests that the major seven clades appeared 50-30 million years ago (Ma) in the Paleogene Period. The Microsphaera lineage may have split from the Uncinula lineage at the boundary of the Paleogene and Neogene, when appendages with dichotomously branched tips appeared. The clade of the species on Nothofagus split from the northern hemisphere species about 20-10 million years ago
\end{abstract}

Submitted 18 Mar 2015; accepted for publication 25 May 2015.

${ }^{1}$ Corresponding author. E-mail: takamatu@bio.mie-u.ac.jp
(Ma) in the Miocene Epoch, and host-shift from trees to herbs also might have occurred in this period.

Key words: 28S rDNA, appendage, host relationship, ITS, molecular clock, powdery mildew

\section{INTRODUCTION}

The fungi known as powdery mildews belonging to the Erysiphaceae (Erysiphales) are exclusively obligate biotrophic parasites of plants. They infect ca. 10000 species of angiosperms, and so far 16 genera containing 876 species, including species known only as an anamorph, have been described worldwide (Amano 1986, Braun and Cook 2012). Molecular phylogenetic analyses revealed that powdery mildews form a distinct monophyletic clade and no other fungi are included in this clade (Mori et al. 2000a, b; Wang et al. 2006a, b). Powdery mildews have some unique characteristics such as ectotrophy and dry atmosphere tolerance, in addition to obligate biotrophy (Takamatsu 2004). These unique characteristics may have been acquired by the common ancestor only once and have been retained during the past 100 million years of the evolutionary history of the Erysiphaceae (Takamatsu 2013a). Phylogeny and evolution of this fungal group have been discussed based on the molecular phylogenetic analyses using the nucleotide sequences of the rDNA region (Takamatsu 2004, 2013a, b). Taxonomy of the powdery mildews has been largely changed based on these analyses as well as morphological observations during the past quarter century (Cook et al. 1997, Braun 1999, Saenz and Taylor 1999, Braun and Takamatsu 2000, Braun and Cook 2012).

The genus Erysiphe is the largest in the Erysiphales containing more than $50 \%$ of all species and consists of five morphological sections, namely sect. Erysiphe with polyascal chasmothecia with mycelioid appendages, sect. Microsphaera with appendages with dichotomously branched apices, sect. Uncinula with appendages with uncinate, circinate or helicoid apices, sect. Typhulochaeta with apical cells in the upper half and sect. Californiomyces with a single peridia cell layer and simple, mycelioid appendages. Because the genus Erysiphe contains species with morphologically different appendages and a wide range of hosts from trees to herbs, this genus is a good model for a discussion on the evolutionary relationships between hosts and appendage morphology. 
However, no comprehensive phylogenetic analysis of this genus has been done so far due to its large size. This was attempted for the first time in this study. Because the genus Erysiphe is too large to discuss the whole phylogeny within a single paper, we divided it into two phylogenetic lineages, namely Microsphaera lineage and Uncinula lineage. As described in detail by Takamatsu et al. (2015), the Microsphaera lineage is a monophyletic group situated at a derived position of the genus Erysiphe and consists of all species of sect. Microsphaera and a large part of sect. Erysiphe and the Uncinula lineage contains all species of sects. Uncinula, Californiomyces and Typhulochaeta as well as some species of sect. Erysiphe and occupies the basal position in the genus Erysiphe (Meeboon and Takamatsu 2015). In Takamatsu et al. (2015), we discussed the phylogeny of the Microsphaera lineage and especially the relationships between sects. Microsphaera and Erysiphe, relationships between appendage morphology and hosts and geographic distributions based on ca. 400 sequences from nuc ITS1-5. 8S-ITS2 and 28S rDNA regions. In this study we conducted phylogenetic analyses of the Uncinula lineage using a total of 167 sequences of nuc ITS15.8S-ITS2 and 28S rDNA regions and included 29 sequences of the Microsphaera lineage and four sequences of the outgroup taxa. This study was conducted to: (i) reveal the phylogenetic structure of the Uncinula lineage, (ii) resolve the phylogenetic relationships between the Microsphaera and Uncinula lineage, (iii) discuss the evolution of appendage morphology based on its relationship with host plants and (iv) discuss the biogeography of the Uncinula lineage.

\section{MATERIALS AND METHODS}

Sample sources.-Host plants, locations of collections and accession numbers of the nucleotide sequence databases (DDBJ, EMBL, and GenBank) are provided (SUPPLEMENTARY TABLE I). The sequences determined in this study were registered in DDBJ under accession numbers LC028946LC029005. Specimens were assigned to the genus Erysiphe and, if chasmothecia were present, to a relevant section, according to the criteria described in INTRODUCTION.

Molecular phylogenetic analyses.-DNA sequences were determined according to the procedures described in Takamatsu et al. (2015). Phylogenetic trees were obtained from the data with maximum parsimony (MP) and maximum likelihood (ML) analyses. MP analysis was performed in PAUP* 4.0a140 (Swofford 2002) with the heuristic search option using the tree bisection reconstruction (TBR) algorithm. This search was repeated 100 times with different random starting points, using the stepwise addition option to increase the likelihood of finding the most parsimonious tree. Branch swapping time was restricted within $60 \mathrm{~s}$ for each replicate. All sites were treated as unordered and unweighted, with gaps treated as missing data. The strength of the internal branches of the trees was tested with bootstrap (BS) analysis (Felsenstein 1985) using 1000 replications with the maximum tree number set as 10. Tree scores, including tree length, consistency index $(\mathrm{CI})$, retention index (RI) and rescaled consistency index (RC), also were calculated. The ML analysis was done with raxmlGUI (Silvestro and Michalak 2012), under a GTRGAMMA model. The BS supports and trees were obtained by running rapid bootstrap analysis of 1000 pseudoreplicates followed by a search for the tree with the highest likelihood.

The Uncinula lineage occupies a basal position in the genus Erysiphe, which suggests an early origin of this group in the evolution of powdery mildews. Actually ITS sequences were too divergent to construct unambiguous alignments for the whole Uncinula lineage sequences. Thus our first strategy was to construct a backbone tree with the 28S rDNA dataset, then to conduct detailed analyses within the respective clades within this tree using ITS + 28S rDNA combined datasets. However, because it was revealed that the 28S rDNA dataset contains only inadequate phylogenetic information, we tried to construct backbone trees with three datasets: (i) ITS dataset, (ii) $28 \mathrm{~S}$ rDNA data set and (iii) combined ITS + $28 \mathrm{~S}$ rDNA dataset. Four sequences from Phyllactinia moricola (D84385, AB022401 ([ITS, 28S]), Leveillula taurica (AB000940, AB022387), Golovinomyces circumfusus (AB000934, $\mathrm{AB} 022360)$ and G. orontii (AB022413, AB022412) were used as outgroup taxa based on Mori et al. (2000a). We used MUSCLE (Edgar 2004) implemented in MEGA 6 (Tamura et al. 2013) for alignment of these datasets and all aligned sites were used for the analyses according to the report that the deletion of gapped sites universally decreases tree resolution (Nagy et al. 2012). We constructed three further data sets without E. actinidiae sequences and subjected them to MP and ML analyses. Consequently we performed a total of 12 phylogenetic analyses using six different data sets to construct backbone trees. Based on the general agreement of the backbone trees, we separated the Uncinula lineage into three small datasets: (i) with clades 1-5, (ii) with Clade 6 and (iii) with Clade 7 . These datasets were aligned by MUSCLE. The alignments were carefully edited manually, and ambiguously aligned sites were deleted from the following analyses. The partition homogeneity test (Farris et al. 1995) was conducted by PAUP* to determine whether the ITS and 28S rDNA datasets were in conflict using 1000 replicates. These alignments were deposited in TreeBASE (http://www.treebase.org/) under accession number S17144.

Topology tests were conducted against a hypothetical phylogeny by the Wilcoxon signed ranks (Templeton 1983), Kishino-Hasegawa (KH, Kishino and Hasegawa 1989) and Shimodaira-Hasegawa (SH, Shimodaira and Hasegawa 1999) tests. A user-defined constraint tree first was drawn with Mesquite 2.75 (Maddison and Maddison 2011), and then the most parsimonious tree consistent with the constraint tree was found with the heuristic search using PAUP*. We compared the hypothetical tree to see whether our data were more likely with the most parsimonious tree 
TABLE I. Summary of backbone tree analyses with six datasets and two tree constructing methods (missing data are shown as gaps)

\begin{tabular}{|c|c|c|c|c|c|c|}
\hline & \multicolumn{3}{|c|}{+ E. actinidiae } & \multicolumn{3}{|c|}{ - E.actinidiae } \\
\hline & ITS & $28 \mathrm{~S}$ rDNA & $\mathrm{ITS}+28 \mathrm{~S}^{\mathrm{a}}$ & ITS & $28 \mathrm{~S}$ rDNA & $\mathrm{ITS}+28 \mathrm{~S}^{\mathrm{a}}$ \\
\hline Sequence number & 160 & 134 & 167 & 158 & 132 & 165 \\
\hline Character number & 997 & 867 & 1864 & 887 & 826 & 1713 \\
\hline Constant site & 281 & 599 & 880 & 270 & 583 & 853 \\
\hline Variable site & 716 & 268 & 984 & 617 & 243 & 860 \\
\hline Informative site & 535 & 179 & 714 & 505 & 166 & 671 \\
\hline \multirow{5}{*}{$\begin{array}{l}\text { Tree length } \\
\text { Consistency index } \\
\text { Retention index } \\
\text { Rescaled consistency } \\
\quad \text { index }\end{array}$} & 3901 & 886 & 4857 & 3787 & 804 & 4675 \\
\hline & 0.3563 & 0.4368 & 0.3659 & 0.3385 & 0.4216 & 0.3467 \\
\hline & 0.7621 & 0.7943 & 0.7627 & 0.7661 & 0.7984 & 0.7654 \\
\hline & & & & 0.2593 & & \\
\hline & 0.2716 & 0.3470 & 0.2791 & & 0.3367 & 0.2654 \\
\hline \multicolumn{7}{|c|}{ Bootstrap support (MP/ML) } \\
\hline Clade 1 & $100 / 100$ & $-^{\mathrm{a}}$ & $100 / 100$ & $100 / 100$ & $-^{\mathrm{a}}$ & $100 / 100$ \\
\hline Clade 2 & $\underline{-a}^{\mathrm{a}}$ & $100 / 100$ & $96 / 100$ & $\underline{-}^{\mathrm{a}}$ & $100 / 100$ & $96 / 100$ \\
\hline Clade 3 & $87 / 97$ & $100 / 100$ & $90 / 100$ & $96 / 95$ & $100 / 100$ & $98 / 100$ \\
\hline Clade 4 & $100 / 100$ & $100 / 98$ & $97 / 100$ & $99 / 100$ & $100 / 100$ & $97 / 100$ \\
\hline Clade 5 & $100 / 100$ & $100 / 100$ & $100 / 100$ & - & - & - \\
\hline Clade 6 & $-/-^{c}$ & $-/-^{\mathrm{b}}$ & $-/-^{\mathrm{d}}$ & $53 / 87$ & $-/-b$ & $58 / 94$ \\
\hline Clade 7 & $93 / 95$ & $<50 / 83$ & $85 / 100$ & $89 / 96$ & $68 / 84$ & $86 / 99$ \\
\hline
\end{tabular}

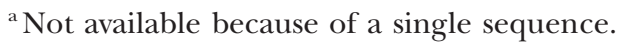

${ }^{\mathrm{b}}$ Clade 6 did not appear in the tree.

${ }^{\mathrm{c}} \mathrm{BS}=72$ in Clade $6+\mathrm{E}$. actinidiae (ML).

${ }^{\mathrm{d}} \mathrm{BS}=84$ in Clade $6+$ E. actinidiae $(\mathrm{ML})$.

using PAUP*. We performed the likelihood ratio test (LRT) to check whether a molecular clock hypothesis is applicable for the dataset.

Geographic distributions of powdery mildews and their hosts. The number of fungal species belonging to the Uncinula lineage and their geographic distributions were counted based on Braun and Cook (2012) and some recent reports (Divarangkoon et al. 2011; Meeboon et al. 2012, 2013; Meeboon and Takamatsu 2013a, b, c, 2015). The world was divided into nine regions based on Amano (1986). The number of host species were extracted from the database "Host plants of the powdery mildew fungi 1.0" (available from the corresponding author upon request), which was based on the Amano (1986) table "Host plants of powdery mildew fungi and their distribution by country" and supplemented with the recent reports. Questionable records in Amano (1986) were deleted.

\section{RESULTS}

Backbone tree.-To find the general clustering in the Uncinula lineage, we tried to construct backbone trees with six datasets and two tree-constructing algorithms (TABLE I). As a result seven major clades were generated in most of the analyses (FIG. 1). Clades 1-5 were constantly supported by strong BS values in all of the 12 analyses. Clade 6 did not appear in the $28 \mathrm{~S}$ rDNA datasets (both datasets with
E. actinidiae and without E. actinidiae) and BS supports of Clade 7 were lower in the 28S rDNA datasets than those of ITS and ITS+28S rDNA datasets. The two sequences from E. actinidiae were much longer than other sequences of the Uncinula lineage. Alignments including E. actinidiae sequences required 110 and 41 additional gaps, and the resulting trees revealed unusual long-branch leading to E. actinidiae. We thus constructed three additional datasets without $E$. actinidiae sequences and used them for MP and ML analyses. Consequently Clade 6 appeared in ITS and ITS+28S rDNA datasets with moderate (MP) and strong (ML) BS supports.

Analyses within the respective clades. - Based on the results of backbone tree analyses, the ITS+28S rDNA combined dataset was divided into three parts. The data set of clades 1-5 consisted of 24 sequences and 1608 characters, of which $636(39.6 \%)$ characters were variable and $440(27.4 \%)$ characters were informative for parsimony analysis. The four outgroup sequences used in the backbone tree analyses were used as outgroup taxa again. A total of 1335 equally parsimonious trees with 1209 steps were constructed by the MP analysis. We illustrated one of the 1335 trees (FIG. 1). All clades (1-5) were strongly supported with more than $92 \%$ BS values in 


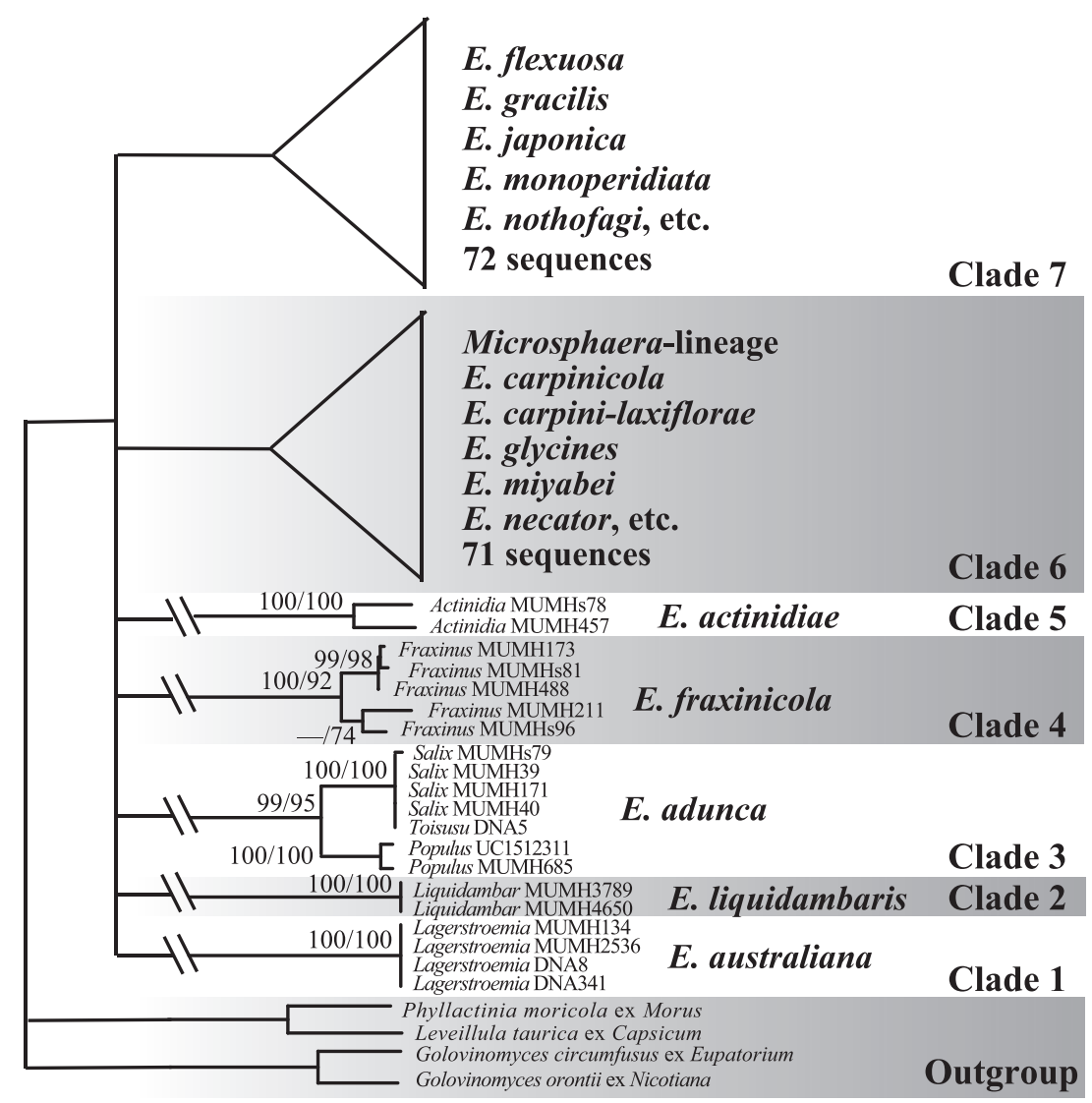

FIG. 1. General agreement tree of the Uncinula lineage constructed by six datasets of the rDNA ITS regions and the divergent domains D1 and D2 sequences of the 28S rDNA, and two tree-constructing methods. The trees within clades 1-5 were constructed by a different dataset consisting of the sequences from clades $1-5$. BS $(>70 \%)$ values by the maximum parsimony (MP) and maximum likelihood (ML) methods are on the respective branch.

both MP and ML analyses. Because the branching order among the clade was not supported, it was ignored (FIG. 1).

Clade 6 is large, consisting of 71 sequences from 18 species of the Uncinula lineage, such as E. carpinicola, E. carpini-laxiflorae, E. miyabei on Betulaceae, E. glycines on Fabaceae, E. necator on Vitis spp., and species from the Microsphaera lineage. The ITS+28S rDNA combined dataset consisted of 72 sequences and 1590 characters including a sequence of E. fraxinicola used as outgroup, of which 173 characters at the 3 '- end of ITS2 region were removed from the phylogenetic analyses due to ambiguous alignment. Of the remaining 1417 characters, 456 $(32.2 \%)$ characters were variable and 335 (23.6\%) characters were informative for parsimony analysis. A total of 580875 equally parsimonious trees with 1443 steps were constructed by the MP analysis. One of the trees is illustrated (FIG. 2).

Clade 7 is large, composed of 72 sequences. The ITS+28S rDNA combined dataset consists of 73 sequences and 1494 characters including a sequence of $E$. arcuata used as outgroup, of which 89 characters at the $3^{\prime}$ - end of ITS2 region were removed from the phylogenetic analyses due to ambiguous alignment. Of the remaining 1405 characters, 397 (28.3\%) were variable and 266 (18.9\%) were informative for parsimony analysis. A total of 889010 equally parsimonious trees with 821 steps were constructed by the MP analysis. One of the trees is illustrated (FIG. 3).

Molecular clock analysis. - ITS sequences evolve too fast to obtain an unambiguous alignment of the whole Uncinula lineage. We thus used only the 28S rDNA sequences for the molecular clock analysis. Because LRT significantly rejected the molecular clock of the 28S rDNA dataset, extremely long or short branches were removed from the dataset until the LRT did not reject the molecular clock hypothesis. Consequently a dataset consisting of 87 sequences was used for the analyses. The molecular clock of the $28 \mathrm{~S}$ rDNA region $\left(6.5 \times 10^{-10}\right.$ substitutions per site per year) was used to calculate evolutionary timing (Takamatsu and Matsuda 2004). The analysis 


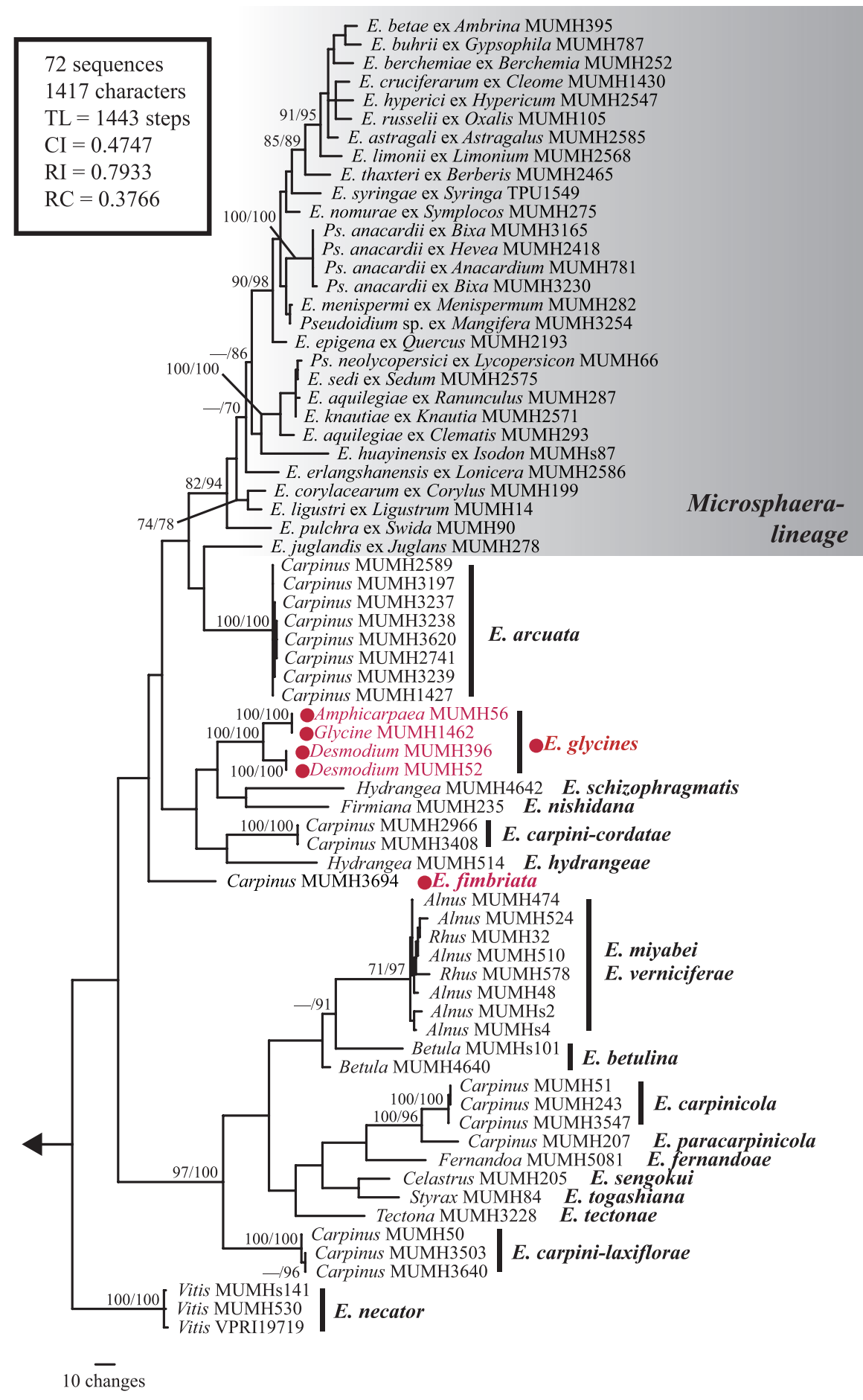

FIG. 2. Clade 6 of the phylogenetic tree of the Uncinula lineage of the genus Erysiphe inferred from the combined dataset of the rDNA ITS regions and the divergent domains D1 and D2 sequences of the 28S rDNA. This tree is a phylogram of one of the 580875 most parsimonious trees with 1443 steps, which was found with a heuristic search by PAUP*. Horizontal branch lengths are proportional to the number of substitutions that were inferred to have occurred along a particular branch of the tree. Presence or absence of circles in front of host names indicate herbaceous or woody plants, respectively. Presence or absence of circles in front of fungal names indicate sects. Erysiphe or Uncinula, respectively (sects. Californiomyces and Typhulochaeta are indicated in another way). In the color version, black and red characters of host names also indicate woody and herbaceous plants, respectively, and black and red characters of fungal names indicate sects. Uncinula and Erysiphe, respectively. 


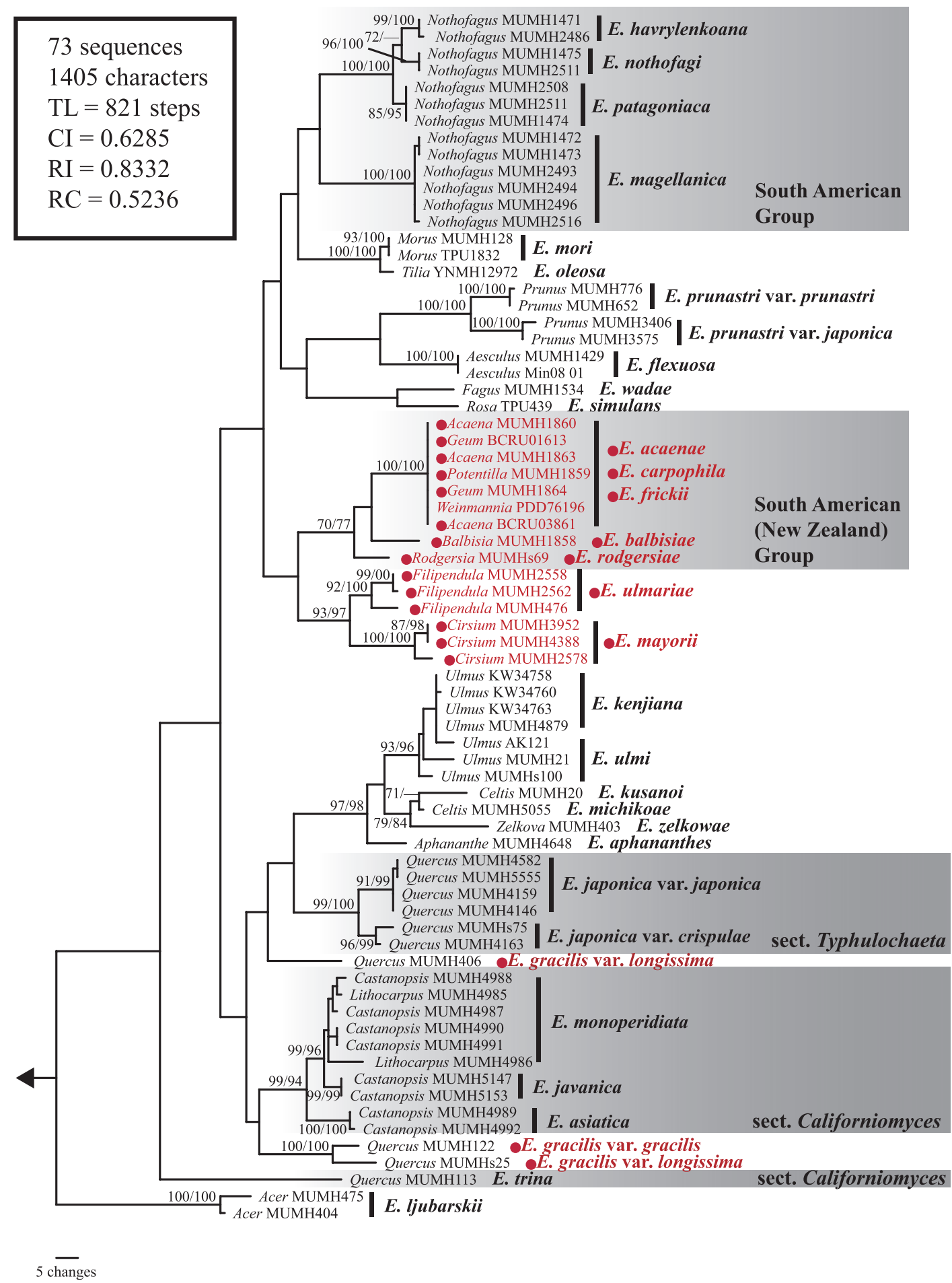

FIG. 3. Clade 7 of the phylogenetic tree of the Uncinula lineage of the genus Erysiphe inferred from the combined dataset of the rDNA ITS regions and the divergent domains D1 and D2 sequences of the 28S rDNA. This tree is a phylogram of one of the 889010 most parsimonious trees with 821 steps, which was found with a heuristic search by PAUP*.

suggested that the seven major clades appeared 50-30 million years ago (Ma) in the Paleogene Period (FIG. 4). The Microsphaera lineage might have split from the Uncinula lineage at the transition from the
Paleogene to the Neogene period, when appendages with dichotomously branched tips first appeared. The clade of the species on Nothofagus split from the northern hemisphere species 20-10 Ma in the 


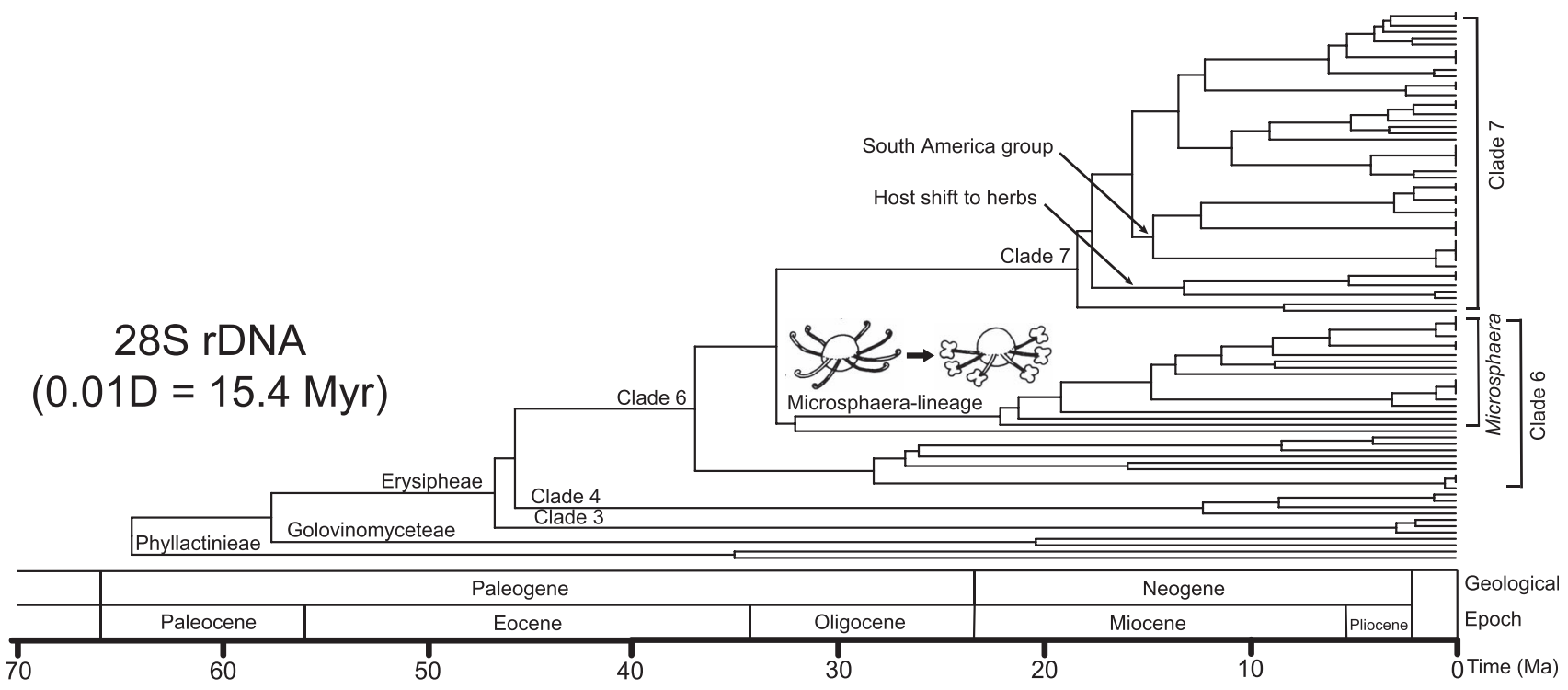

FIG. 4. Estimated dates of divergence of major groups of the Uncinula lineage of the genus Erysiphe based on the nucleotide sequences of the $28 \mathrm{~S}$ rDNA region, and nucleotide substitution rates of the Erysiphaceae reported by Takamatsu and Matsuda (2004). Ma = million years ago.

Miocene Epoch, and host-shift from trees to herbs also might have occurred in this period. This timing of host shift in the Uncinula lineage coincides with the timing of the host-shifts that occurred in the Microsphaera lineage (Takamatsu et al. 2015).

\section{DISCUSSION}

Species of the Uncinula lineage and their host plants. The number of species of the Uncinula lineage was counted based on Braun and Cook (2012) (TABLE II). Records reported by Divarangkoon et al. (2011), Meeboon et al. (2012, 2013) and Meeboon and Takamatsu (2013a, b, c, 2015) were added to the total number (TABLE II). Because it is not unambiguously known which species in sect. Erysiphe listed by Braun and Cook (2012) belong to the Uncinula lineage, only the species we examined were included in this analysis. Therefore we might have underestimated the number of species in sect. Erysiphe. In our analysis the number of species belonging to the Uncinula lineage was 141 in total, 121 in sect. Uncinula, 10 in sect. Erysiphe, six in sect. Californiomyces and four in sect. Typhulochaeta. When the geographic distributions of these species in Braun and Cook (2012) were divided into nine regions of the world according to Amano (1986), eastern Asia had the highest number (79), followed by southeastern/southern Asia with 30 known species. This number was between 12 and 16 in central/western Asia, Europe, North America, South America and Africa. Only three species were recorded from Oceania. When the number of species specific (i.e. apparently endemic) to each single region was counted, eastern Asia had the highest number, $67(84 \%)$ of the 79 species recorded in the region, followed by 14 (88\%), 11 (73\%), and 18 $(60 \%)$ in South America, Africa and southeast/ southern Asia, respectively. Whereas they were one $(8 \%)$, two $(13 \%)$ and seven $(54 \%)$ in central/western Asia, Europe and North America.

A total of 87 Uncinula species (including Uncinuliella and Bulbouncinula) were described in Braun (1987), and this number increased to 121 species assigned to sect. Uncinula in Braun and Cook (2012), indicating that 34 species of Erysiphe sect. Uncinula were newly described during the past quarter century. Many of them were described from India, Africa and peripheral areas of China where comprehensive mycological surveys have been conducted only rarely. This suggests that many more new species of this morphological group will be described from these areas in the future. Consequently it is clear that eastern Asia has the richest biota of the Uncinula lineage in the world but this does not imply that eastern Asia is the geographic origin of this lineage. Global cooling of the Earth occurred during the Paleogene Period until the time divergence of powdery mildews happened. Migration of deciduous tree flora occurred southward in the northern hemisphere in association with global cooling. Powdery mildews have might also migrated southward with their host plants and many species in the Uncinula lineage now survive as relicts in eastern Asia, which is the largest refugium in the world (Tiffney 1985a, b; Manchester 1999; Wen 1999; Tiffney and Manchester 2001). Species of the Uncinula lineage that migrated to the respective regions might have diverged 
TABLE II. Number and geographic distributions of species belonging to the Uncinula-lineage and their host plants ${ }^{\mathrm{a}}$

\begin{tabular}{|c|c|c|c|c|c|c|c|c|c|c|}
\hline Section & & World & $\begin{array}{c}\text { Eastern } \\
\text { Asia }\end{array}$ & $\begin{array}{c}\text { Southeast/ } \\
\text { southern } \\
\text { Asia }\end{array}$ & $\begin{array}{c}\text { Central- } \\
\text { western } \\
\text { Asia }\end{array}$ & Europe & $\begin{array}{l}\text { North } \\
\text { America }\end{array}$ & $\begin{array}{l}\text { South } \\
\text { America }\end{array}$ & Africa & Oceania \\
\hline \multirow[t]{3}{*}{ Uncinula } & $\begin{array}{l}\text { Number of fungal } \\
\text { species }\end{array}$ & 121 & 69 & 26 & 10 & 13 & 10 & 13 & 15 & 2 \\
\hline & $\begin{array}{l}\text { Species specific to } \\
\text { the region }\end{array}$ & & 60 & 14 & 1 & 2 & 5 & 11 & 11 & 0 \\
\hline & $\begin{array}{l}\text { Number of host } \\
\text { species }^{\text {b }}\end{array}$ & 527 & 236 & 31 & 50 & 122 & 122 & 29 & 28 & 5 \\
\hline \multirow[t]{3}{*}{ Erysiphe } & $\begin{array}{l}\text { Number of fungal } \\
\text { species }\end{array}$ & 10 & 6 & 0 & 2 & 2 & 1 & 3 & 0 & 1 \\
\hline & $\begin{array}{l}\text { Species specific to } \\
\text { the region }\end{array}$ & & 3 & 0 & 0 & 0 & 0 & 3 & 0 & 1 \\
\hline & $\begin{array}{l}\text { Number of host } \\
\text { species }\end{array}$ & 82 & 48 & 0 & 4 & 18 & 7 & 11 & 0 & 1 \\
\hline \multirow[t]{3}{*}{ Californiomyces } & $\begin{array}{l}\text { Number of fungal } \\
\text { species }\end{array}$ & 6 & 1 & 4 & 0 & 0 & 1 & 0 & 0 & 0 \\
\hline & $\begin{array}{l}\text { Species specific to } \\
\text { the region }\end{array}$ & & 1 & 4 & 0 & 0 & 1 & 0 & 0 & 0 \\
\hline & $\begin{array}{l}\text { Number of host } \\
\text { species }\end{array}$ & 17 & 1 & 10 & 0 & 0 & 6 & 0 & 0 & 0 \\
\hline \multirow[t]{3}{*}{ Typhulochaeta } & $\begin{array}{l}\text { Number of fungal } \\
\text { species }\end{array}$ & 4 & 3 & 0 & 0 & 0 & 1 & 0 & 0 & 0 \\
\hline & $\begin{array}{l}\text { Species specific to } \\
\text { the region }\end{array}$ & & 3 & 0 & 0 & 0 & 1 & 0 & 0 & 0 \\
\hline & $\begin{array}{l}\text { Number of host } \\
\text { species }\end{array}$ & 10 & 9 & 0 & 0 & 0 & 1 & 0 & 0 & 0 \\
\hline \multirow[t]{3}{*}{ Total } & $\begin{array}{l}\text { Number of fungal } \\
\text { species }\end{array}$ & 141 & 79 & 30 & 12 & 15 & 13 & 16 & 15 & 3 \\
\hline & $\begin{array}{l}\text { Species specific to } \\
\text { the region }\end{array}$ & & 67 & 18 & 1 & 2 & 7 & 14 & 11 & 1 \\
\hline & $\begin{array}{l}\text { Number of host } \\
\text { species }\end{array}$ & 636 & 294 & 41 & 54 & 140 & 136 & 40 & 28 & 6 \\
\hline
\end{tabular}

\footnotetext{
${ }^{a}$ Number of species based on Braun and Cook (2012) and supplemented with recent reports.

${ }^{\mathrm{b}}$ Number of host species based on Amano (1986) and supplemented with recent reports. Questionable data in Amano (1986) are deleted.
}

into the species specific to each region. For example powdery mildews on Nothofagus form a monophyletic group. These fungi might have developed into four species on Nothofagus in South America. In addition, herb-parasitic species of the Uncinula lineage (viz. E. acaenae, E. frickii, E. balbisiae) also might have evolved in South America. Although African species were not included in this study, analyses of those species will provide further insights in phylogeny and evolution of the Uncinula lineage.

A total of 636 plant species covering 48 families have been reported as hosts of the Uncinula lineage (SupPlementary table II). Of these the Salicaceae has the largest number of host species (172), followed by the Fagaceae (65), Rosaceae (42), Vitaceae (39), Fabaceae (35), Betulaceae (33), Ulmaceae (32), Sapindaceae (30) and Asteraceae (26). Hosts of species belonging to sects. Uncinula, Californiomyces and Typhulochaeta are trees or bushes, and those of sect. Erysiphe are herbs in the Rosaceae, Fabaceae and Asteraceae. Whereas E. gracilis belonging to sect. Erysiphe infects evergreen Quercus species of the Fagaceae. Consequently most species of the Uncinula lineage are tree-parasitic with only a few infecting herbaceous hosts.

Phylogeny of the Uncinula lineage.-Clades 1-5: As a result of backbone tree analyses sequences of the Uncinula lineage in this study were divided into seven distinct clades. The branching order of the seven clades was inconsistent among datasets and analyses. However, E. australiana (Clade 1) first split from the remaining taxa. A unique "fluted" pattern on conidial cell walls (Cook et al. 1997, Braun and Cook 2012) may support the isolated position of this species. Next 
to split were E. liquidambaris (Clade 2), E. adunca (Clade 3) or E. fraxinicola (Clade 4). Placement of E. actinidiae (Clade 5) varied according to the datasets and analyses. clades 6 and 7 were situated mostly at a derived position. Each clade from clades 1-5 consisted of a single fungal species infecting a single host family. Clade 1 contained four identical sequences of E. australiana on Lagerstroemia indica and Clade 2 was composed of two identical 28S rDNA sequences of E. liquidambaris on Liquidambar spp. Clade 3 consisted of seven sequences of $E$. adunca on hosts of the Salicaceae. This clade split into two distinct subclades (viz. one consisting of isolates from Salix and Toisusu and the other isolates from Populus). MUMH685 is an isolate from $P$. nigra from Hungary. Two other Erysiphe sect. Uncinula species have been reported on this host, namely E. adunca and E. populicola, the latter from India and not from Europe (Braun and Cook 2012). Because MUMH685 is an anamorphic specimen, species identification was impossible. The sequence of UC1512311 was reported as E. adunca in Saenz and Taylor (1999), but the morphology of this specimen is unknown. We thus tentatively identified both subclades as E. adunca. Clade 4 contains E. fraxinicola on Fraxinus spp. (Oleaceae). This clade also is divided into two subclades but no difference in hosts and collection places could be found between them. Clade 5 contains two sequences from E. actinidiae from Actinidia spp. (Actinidiaceae). These were much longer than those from other species of the Uncinula lineage, and many gaps are inserted in the alignment. The sequence similarities between the two E. actinidiae isolates from Actinidia arguta and A. polygama were only $85.0 \%$ in ITS and $97.6 \%$ in the $28 \mathrm{~S}$ rDNA sequences, suggesting that their genetic distance was higher than commonly seen at species level. Additional sequences as well as morphological examinations are necessary for further conclusions.

Clade 6: The Microsphaera lineage formed a monophyletic clade within Clade 6 with strong BS supports (BS = 82/94; MP/ML) excluding E. juglandis in MP analysis. Although all species of the Microsphaera lineage including $E$. juglandis formed a monophyletic clade in ML analysis, the BS support was low. To check whether our dataset could significantly reject monophyly of the Microsphaera lineage in MP analysis, we conducted the Wilcoxon signed-ranks test (Templeton 1983). A hypothetical tree based on the assumption that the Microsphaera lineage would form a monophyletic clade was constructed with 1444 steps, only one step longer than the best MP tree. The Wilcoxon signed-ranks test could not reject this hypothetical tree (SuPPlEMENTARY TABLE III). Considering the morphological characteristics it is highly likely that the Microsphaera lineage is monophyletic. A sister group to the Microsphaera lineage was E. arcuata in the MP analysis. However, this was not supported by BS value and ML analysis resulted in a different branching order. Therefore the closest relative to the Microsphaera lineage is not clear. Among species of Clade 6, E. glycines is interesting because only this species infects herbaceous plants within this group. This species belongs to sect. Erysiphe and forms simple, mycelioid appendages from the lower part of chasmothecia. Chasmothecia produce anchoring hyphae mostly from the lower part to settle young chasmothecia on the leaf surface. In sects. Uncinula and Microsphaera anchoring hyphae are easily distinguishable from appendages by morphological differences. However, in sect. Erysiphe this is sometimes difficult because anchoring hyphae and appendages are both mycelioid. The most distinct difference between anchoring hyphae and appendages is the timing of production. Anchoring hyphae start to elongate from chasmothecial primordia in the early stage of formation. On the other hand appendages start to elongate from pigmented chasmothecia at a later stage. Observations of the process of chasmothecium formation by SEM revealed a clear appendage formation in some species of sect. Erysiphe. However, this was not observed in E. glycines (S. Takamatsu unpubl). Although appendages of E. glycines are described as mycelioid type in Braun and Cook (2012), this species might not have true appendages.

Previously Erysiphe on Carpinus was regarded as the single species, E. carpinicola. However, E. carpinicola was separated into three species by each host species based on molecular and morphological analyses (Braun et al. 2006). A total of seven Erysiphe species belonging to the Uncinula lineage have been described on Carpinus (Takamatsu et al. 2008, Braun and Cook 2012, Meeboon and Takamatsu 2013). Of the seven species all six analyzed in this study belong to Clade 6, but they did not group in a single clade. We constructed a hypothetical tree based on the assumption that Erysiphe spp. on Carpinus would form a monophyletic clade and examined whether our dataset can significantly reject the hypothetical tree by the Wilcoxon signed-ranks test. Consequently the Wilcoxon signed-ranks test significantly rejected monophyly of the Carpinus powdery mildew species (SUPPLEMENTARY TABLE III). KH and $\mathrm{SH}$ tests also strongly rejected the hypothetical tree. This result suggests that the set of Erysiphe species on Carpinus spp. are polyphyletic or paraphyletic. If the former idea is true, powdery mildew fungi might have jumped on Carpinus multiple times independently. If the latter idea is true, a common ancestor might 
have infected Carpinus and then have undergone host shifts to other plant families as well as speciation on Carpinus hosts. Considering the similar morphological characteristics of the species on Carpinus, such as anchoring hyphae arising from the upper part of chasmothecia (secondary appendages) and appendage shape, the latter explanation may be more likely. Within Clade 6, 21 sequences, including E. carpinicola, E. paracarpinicola, E. carpini-laxiflorae and E. miyabei, form a subclade with strong supports $(\mathrm{BS}=97 / 100 \%, \mathrm{MP} / \mathrm{ML})$. This subclade appeared constantly in all analyses in this study. However, we could not find any correlation of this subclade to host phylogeny or biogeography.

Clade 7: Representatives of plant families, such as Fagaceae, Ulmaceae, Cannabaceae, Rosaceae, Nothofagaceae, Sapindaceae and Asteraceae, are included in Clade 7 as hosts, and sequences of isolates from a single host family usually formed small groups. This suggests that the fungi of this clade evolved closely related with plant phylogeny. Most plant families included in this clade belong to the orders Fagales and Rosales from the Eurosids I in APG III (Haston et al. 2009). This is in contrast with Clade 6 that contains a wide range of host families. A monophyletic group consisting of 15 sequences from herbparasitic species is included in this clade. This suggests that host shift from trees to herbs occurred only once within this clade and speciation occurred as host ranges expanded on herbaceous hosts. Although a host shift from trees to herbs occurred many times in the Microsphaera lineage, this happened in clades 6 as well as 7 of the Uncinula lineage. Within this herbaceous host group, four species collected in the southern hemisphere (viz. E. balbisiae, E. acaenae, E. frickii, E. carpophilla) grouped into a clade. Erysiphe acaenae, E. frickii and Erysiphe sp. on Potentilla collected in Argentina had identical rDNA sequences, although they were described as different species and infect different plant genera in the Rosaceae. In addition, a sequence deposited in DNA databases as E. carpophila on Weinmannia silvicola from New Zealand also has an ITS sequence identical to the above sequences. Weinmannia silvicola is a woody plant, a native of New Zealand belonging to the Cunoniaceae. It is curious that this fungus has a sequence identical to the fungi on rosaceous hosts from South America.

The four species occurring on Nothofagus in Argentina formed a subclade in Clade 7, which suggests that an ancestral fungus of these species infected Nothofagus only once and developed into four species. These three, in addition E. magellanica, have coiled spring-like appendages. The tree topology showing that E. magellanica split first from the other three species agrees well with appendage morphology.

Evolution of appendage morphology.-Appendages of chasmothecia have long been regarded as an important morphological character to distinguish genera of powdery mildews. However, molecular phylogenetic analyses did not support the traditional taxonomic system based on appendage morphology (Mori et al. 2000a). Especially taxonomy within the tribe Erysipheae has been largely changed during the past $20 \mathrm{y}$ (Braun 1999, Braun and Takamatsu 2000, Braun and Cook 2012). For example the genera Microsphaera and Uncinula were reduced to synonymy with Erysiphe and just treated as morphological, non-phylogenetic sections (Braun and Takamatsu 2000). The simple mycelioid appendages of species in sect. Erysiphe is a result of adaptive evolution to their hosts (Mori et al. 2000a, Takamatsu 2004). Therefore, species of sect. Erysiphe are separated into many small clades that form a complicated polyphyly due to convergent evolution intermixed with species of sects. Microsphaera and Uncinula.

Uncinula-type appendages are regarded as the most ancestral character in powdery mildews (Mori et al. 2000a). For example the genera Caespitotheca and Parauncinula, situated at the most basal positions of powdery mildews have Uncinula-type appendages (Takamatsu et al. 2005a, b). The genera Sawadaea and Pleochaeta, having Uncinula-type appendages, are situated at basal positions in the tribes Cystotheceae and Phyllactinieae, respectively (Mori et al. 2000a). Taxa with Uncinula type, Microsphaera type and simple, mycelioid Erysiphe type appendages occur together in the genus Erysiphe. Thus the genus Erysiphe is a good model to discuss the evolution of appendage morphology. This study revealed that the taxa with Uncinula-type appendages occupy the basal part of the tree, suggesting that these appendages are indeed the most ancestral in the genus Erysiphe. The taxa with Microsphaera-type appendages having derived from the group with Uncinula-type appendages to form a monophyletic clade suggests that this change of appendage morphology occurred only once during the evolution of the genus Erysiphe. Molecular clock analysis suggests that Microsphaeratype appendages appeared at the transition between the Paleogene and Neogene periods. A climatic deterioration involving a decrease in world temperature and an increase in seasonality that started in the Middle Eocene (ca. $50 \mathrm{Ma}$ ) began again after the middle Miocene (ca. $15 \mathrm{Ma}$ ) and progressed stepwise into the Quaternary Period containing the Pleistocene Epoch and ice ages (Tiffney and Manchester 2001). This led to sequential modernization of the flora 
involving the southward migration of deciduous trees and spread of herbaceous plants during the Neogene Period. These changes in environment and vegetation might be involved in the evolution of Microsphaeratype appendages. However, data to support this hypothesis are too scarce for more detailed discussion.

Chasmothecia have been regarded as overwintering organs of powdery mildews in which appendages play an important role (Takamatsu 2004). Therefore a change of appendage morphology might reflect a change in overwintering strategy. Of the five sections in the genus Erysiphe, Clade 7 contains all of them except sect. Microsphaera. For example E. gracilis (sect. Erysiphe) has simple, mycelioid appendages and infects evergreen trees of the Fagaceae. Erysiphe trina, E. monoperidiata, E. asiatica and E. javanica (all sect. Californiomyces) also infect evergreen trees of Fagaceae and also have simple, mycelioid appendages. These species are closely related in phylogeny, and probably the simple, mycelioid appendages are a result of adaptive evolution for overwintering on evergreen trees in this case. Erysiphe japonica belongs to sect. Typhulochaeta, which is unique in appendage morphology. Species in this section have numerous clubshaped cells (appendages) arising from the upper half of chasmothecia. These cells eject mucilaginous material through ruptured apices (Braun and Cook 2012). Consequently these species have long been classified in a separate genus Typhulochaeta based on the unique morphology. However, this study clearly showed that this species is closely related to other species that infect Fagaceae. It also infects deciduous tree species of this family, such as Quercus serrata and Q. crispula, and is considered to complete its life cycle without an asexual morph (conidia). We can assume that the unique Typhulochaeta type appendage is an adaptation for the maintenance of these species purely by sexual reproduction.

\section{PeRsPective}

Molecular phylogenetic analyses were conducted based on 55 species of the Uncinula lineage in this study. Because 144 species are described in this lineage based on Braun and Cook (2012) and other reports (Divarangkoon et al. 2011; Meeboon et al. 2012, 2013; Meeboon and Takamatsu 2013a, b, c, 2015), this study covers $38 \%$ of the total species of the Uncinula lineage. Since Braun (1987) 34 additional species of sect. Uncinula have been described (Braun and Cook 2012). Most of these species are known only from type specimens with narrow geographic distributions, and so we could not include most of them in the present analyses. These species should be included in future phylogenetic analyses using ITS and $28 \mathrm{~S}$ rDNA sequences and other DNA markers.

\section{ACKNOWLEDGMENTS}

We thank Dr Maria Havrylenko for kindly providing specimens. This work was financially supported in part by a grant-in-aid for Scientific Research (No. 23580061) from the Japan Society for the Promotion of Science, a grant from the Institute for Fermentation, Osaka, Japan, to ST. The support of a visiting professorship (PD-021/2014) of the Hungarian Academy of Sciences (MTA), awarded to ST, also is acknowledged.

\section{LITERATURE CITED}

Amano (Hirata) K. 1986. Host range and geographical distribution of the powdery mildew fungi. Tokyo: Japan Scientific Societies Press. 741 p.

Braun U. 1987. A monograph of the Erysiphales (powdery mildews). Beih Nova Hedwigia 89:1-700.

- 1999. Some critical notes on the classification and generic concept of the Erysiphaceae. Schlechtendalia 3:49-55.

—_ C Cook RTA. 2012. Taxonomic manual of the Erysiphales (powdery mildews). CBS Biodiversity Series No.11. Utrecht, the Netherlands: CBS-KNAW Fungal Biodiversity Centre. 707 p.

— sphaera, Uncinula (Erysipheae) and Cystotheca, Podosphaera, Sphaerotheca (Cystotheceae) inferred from rDNA ITS sequences-some taxonomic consequences. Schlechtendalia 4:1-33.

- - Heluta V, Limkaisang S, Divarangkoon R, Cook RTA, Boyle H. 2006. Phylogeny and taxonomy of powdery mildew fungi of Erysiphe sect. Uncinula on Carpinus species. Mycol Prog 5:139-153, doi:10.1007/ s11557-006-0509-6

Cook RTA, Inman AJ, Billings C. 1997. Identification and classification of powdery mildew anamorphs using light and scanning electron microscopy and host range data. Mycol Res 101:975-1002, doi:10.1017/S095375629 700364X

Divarangkoon R, Meeboon J, Monkhung S, To-anun C, Takamatsu S. 2011. Two new species of Erysiphe (Erysiphales, Ascomycota) from Thailand. Mycosphere 2:231-238.

Edgar RC. 2004. MUSCLE: multiple sequence alignment with high accuracy and high throughput. Nucleic Acids Res 32:1792-1797, doi:10.1093/nar/gkh340

Farris JS, Kallersjö M, Kluge AG, Bult C. 1995. Testing the significance of incongruence. Cladistics 10:315-319, doi:10.1111/j.1096-0031.1994.tb00181.x

Felsenstein J. 1985. Confidence limits on phylogenies: an approach using the bootstrap. Evolution 39:783-791, doi:10.2307/2408678

Haston E, Richardson JE, Stevens PF, Chase MW, Harris DJ. 2009. The linear angiosperm phylogeny group (LAPG) III: a linear sequence of the families in APG III. Bot J Linn Soc 161:128-131, doi:10.1111/j.1095-8339.2009.01000.x

Kishino H, Hasegawa M. 1989. Evaluation of the maximum likelihood estimate of the evolutionary tree topologies from DNA sequence data and the branching order 
in Hominoidea. J Mol Evol 29:170-179, doi:10.1007/ BF02100115

Maddison WP, Maddison DR. 2011. Mesquite 2.75: a modular system for evolutionary analysis. (http://mesquite project.org)

Meeboon J, Divarangkoon R, Takamatsu S. 2013. Two new species of Erysiphe sect. Uncinula (Erysiphales): Erysiphe fernandoae and E. michikoae. Mycoscience 54:2-7, doi:10.1016/j.myc.2012.06.001

— Hidayat I, Takamatsu S. 2012. Erysiphe javanica sp. nov., a new tropical powdery mildew from Indonesia. Mycotaxon 120:189-194, doi:10.5248/120.189

—_, Takamatsu S. 2013a. Molecular phylogeny reveals the presence of cryptic speciation within Erysiphe japonica (三 Typhulochaeta japonica), a powdery mildew on Quercus spp. Mycoscience 54:69-74, doi:10.1016/j. myc.2012.07.003

— - 2013b. Erysiphe paracarpinicola: a new species of Erysiphe sect. Uncinula on Carpinus cordata (Betulaceae). Mycoscience 54:210-216, doi:10.1016/j. myc.2012.08.008

- - - - - 2013c. Erysiphe havrylenkoana and E. prunastri var. japonica: a new species and a new variety of Erysiphe sect. Uncinula (Erysiphaceae, Ascomycota). Mycol Prog 12:277-282, doi:10.1007/s11557012-0832-z

— - 2015. Notes on powdery mildews (Erysiphales) in Japan I. Erysiphe sect. Erysiphe. Mycoscience, doi:10.1016/j.myc.2014.07.004

Mori Y, Sato Y, Takamatsu S. 2000a. Evolutionary analysis of the powdery mildew fungi (Erysiphales) using nucleotide sequences of the nuclear ribosomal DNA. Mycologia 92:74-93, doi:10.2307/3761452

2000b. Molecular phylogeny and radiation time of Erysiphales inferred from the nuclear ribosomal DNA sequences. Mycoscience 41:437-447, doi:10.1007/BF02461662

Nagy LG, Kocsubé S, Csanádi Z, Kovács GM, Petkovits T, Vágvölgyi C, Papp T. 2012. Re-mind the gap! Insertiondeletion data reveal neglected phylogenetic potential of the nuclear ribosomal internal transcribed spacer (ITS) of fungi. PloS One 7:e49794, doi:10.1371/ journal.pone.0049794

Saenz GS, Taylor JW. 1999. Phylogeney of the Erysiphales (powdery mildews) inferred from internal transcribed spacer (ITS) ribosomal DNA sequences. Can J Bot 77: 150-168, doi:10.1139/b01-009

Shimodaira H, Hasegawa M. 1999. Multiple comparisons of $\log$ likelihoods with applications to phylogenetic inference. Mol Biol Evol 16:1114-1116, doi:10.1093/ oxfordjournals.molbev.a026201

Silvestro D, Michalak I. 2012. raxmlGUI: a graphical frontend for RAxML. Org Divers Evol 12:335-337, doi:10. 1007/s13127-011-0056-0

Swofford DL. 2002. PAUP* 4.0b10: phylogenetic analysis using parsimony (*and other methods). Sunderland, Massachusetts: Sinauer Associates.

Takamatsu S. 2004. Phylogeny and evolution of the powdery mildew fungi (Erysiphales, Ascomycota) inferred from nuclear ribosomal DNA sequences. Mycoscience 45: 147-157, doi:10.1007/S10267-003-0159-3
- 2013a. Origin and evolution of the powdery mildews (Ascomycota, Erysiphales). Mycoscience 54: 75-86, doi:10.1016/j.myc.2012.08.004

— 2013b. Molecular phylogeny reveals phenotypic evolution of powdery mildews (Erysiphales, Ascomycota). J Gen Plant Pathol 79:218-226, doi:10.1007/ s10327-013-0447-5

___ Braun U, Limkaisang S. 2005a. Phylogenetic relationships and generic affinity of Uncinula septata inferred from nuclear rDNA sequences. Mycoscience 46:9-16, doi:10.1007/S10267-004-0205-9

— Ito (Arakawa) H, Shiroya Y, Kiss L, Heluta V. 2015. First comprehensive phylogenetic analysis of the genus Erysiphe (Erysiphales, Erysiphaceae) I. The Microsphaera lineage. Mycologia 107:475-489, doi:10.3852/ 15-007

—- Masuya H, Divarangkoon R, Nomura Y. 2008. Erysiphe fimbriata sp. nov. : a powdery mildew fungus found on Carpinus laxiflora. Mycoscience 49:185-191, doi:10.1007/s10267-008-0406-8

— Matsuda S. 2004. Estimation of molecular clocks for ITS and 28S rDNA in Erysiphales. Mycoscience 45:340344, doi:10.1007/S10267-004-0187-7

_, Niinomi S, Cabrera de Álvarez MG, Álvarez RE, Havrylenko M, Braun U. 2005b. Caespitotheca gen. nov., an ancestral genus in the Erysiphales. Mycol Res 109: 903-911, doi:10.1017/S0953756205003047

Tamura K, Stecher G, Peterson D, Filipski A, Kumar S. 2013. MEGA 6: molecular evolutionary genetics analysis 6.0. Mol Biol Evol 30:2725-2729, doi:10.1093/molbev/ mst197

Templeton AR. 1983. Phylogenetic inference from restriction endonuclease cleavage site maps with particular reference to the evolution of humans and the apes. Evolution 37:221-244, doi:10.2307/2408332

Tiffney BH. 1985a. Perspectives on the origin of the floristic similarity between eastern Asia and eastern North America. J Arnold Arbor Harv Univ 66:73-94.

- 1985b. The Eocene North Atlantic land bridge: its importance in tertiary and modern phytogeography of the northern hemisphere. J Arnold Arbor Harv Univ 66:243-273.

— Manchester SR. 2001. The use of geological and paleontological evidence in evaluating plant phylogeographic hypotheses in the northern hemisphere Tertiary. Intern J Plant Sci 162:S3-S17, doi:10.1086/ 323880

Wang Z, Binder M, Schoch CL, Johnston PR, Spatafora JW, Hibbett DS. 2006a. Evolution of helotialean fungi (Leotiomycetes, Pezizomycotina): a nuclear rDNA phylogeny. Mol Phylogenet Evo 41:295-312, doi:10.1016/ j.ympev.2006.05.031

— J Johnston PR, Takamatsu S, Spatafora JW, Hibbett DS. 2006b. Toward a phylogenetic classification of the Leotiomycetes based on rDNA data. Mycologia 98: 1065-1075, doi:10.3852/mycologia.98.6.1065

Wen J. 1999. Evolution of eastern Asian and eastern North American disjunct distributions in flowering plants. Ann Rev Ecol System 30:421-455, doi:10.1146/annurev. ecolsys.30.1.421 